\title{
Macrocyclic derivatives of 6-methyluracil: New ligands of the peripheral anionic site of acetylcholinesterase
}

\author{
K. Petrov* \\ A.E. Arbuzov Institute of Organic and Physical Chemistry, Kazan, Russia \\ *Corresponding author. E-mail: kpetrov2005@mail.ru
}

BACKGROUND: Acetylcholinesterase (AChE) inhibitors are widely used in medicine for pharmacological correction of cholinergic neurotransmission pathologies such as myasthenia gravis (MG) and Alzheimer's disease [1,2]. The efficacy of anti-AChE drugs is based on their ability to potentiate the effects of acetylcholine (ACh) due to a decrease in the rate of AChE-catalyzed hydrolysis of ACh. Crystallographic studies showed that the active site of AChE is located at the bottom of a deep gorge [3]. It was shown that, in addition to its catalytic center, AChE has other sites that are crucial for the proper functioning of the enzyme. In particular, the so-called peripheral anionic site (PAS) located at the entrance of the active site gorge is responsible for: 1) allosteric modulation of the catalytic center; 2) enzyme inhibition at high substrate concentration; 3 ) and non-catalytic functions such as enhancement of cell adhesion and neurite outgrowth.

OBJECTIVE: Especially interesting is the relationship between the PAS and pathological beta-amyloid deposition. This led to a new hypothesis for rational design of more effective anti-Alzheimer drugs [4].

METHODS: Concentration of drug producing 50\% of AChE activity inhibition (IC50) was measured using the method of Ellman et al. [5]. Toxicological experiments were performed using IP injection of the different compounds in mice. LD50, dose (in $\mathrm{mg} / \mathrm{kg}$ ) causing lethal effects in $50 \%$ of animals was taken as a criterion of toxicity [6]. Molecular docking was performed with Autodock 4.2.6 software.

RESULTS: We described previously a new class of selective mammalian AChE vs. butyrylcholinesterase (BChE) inhibitors based on alkylammonium derivatives of 6-methyluracil of acyclic topology [7]. In the present study, taking acyclic derivatives of 6-methyluracil as a model AChE inhibitor, we attempted to develop AChE inhibitors that specifically bind to the PAS with weak binding to the active site of AChE. We attempted to increase the size of AChE ligands to restrict specific binding to the PAS of AChE. To this aim we synthesized pyrimidinophanes bearing two o-nitrobenzylethyldialkylammonium heads. Almost all of synthesized pyrimidinophanes inhibited AChE in the nanomolar range. Based on molecular docking simulations, it was suggested that compounds bind AChE to the active center as well as to the PAS or only to the PAS. Thus, we found that introduction of the spacer, flexible or rigid, between [5-(o-nitrobenzylethylammonium)pentyl] units at $\mathrm{N}$ atoms of the 6-methyluracil moiety allows tuning the binding of 6-methyluracil derivatives with $\mathrm{AChE}$.

CONCLUSIONS: In conclusion, it can be stated that pyrimidinophanes are promising lead scaffold structures for further design of specific ligands for the PAS of AChE. Also AChE inhibitors with a 
6-methyluracil moiety may be considered as potential drugs for the treatment of pathological muscle weakness syndromes.

Keywords: Pyrimidinophanes, beta-amyloid, peripheral anionic site, acetylcholinesterase

Conflict of interest statement: Authors declare no conflict of interests.

\section{References}

[1] Brenner T1, Nizri E, Irony-Tur-Sinai M, Hamra-Amitay Y, Wirguin I. Acetylcholinesterase inhibitors and cholinergic modulation in Myasthenia Gravis and neuroinflammation. J Neuroimmunol. 2008 Sep 15;201-202:121-7. doi: 10.1016/j. jneuroim.2008.05.022. Epub 2008 Aug 5.

[2] Cummings JL. Alzheimer's disease. N Engl J Med. 2004;351:56-67. doi: 10.1056/NEJMra040223

[3] Dvir H, Silman I, Harel M, Rosenberry TL, Sussman JL.. Acetylcholinesterase: from 3D structure to function. Chem Biol Interact. 2010;187(1-3):10-22. doi: 10.1016/j.cbi.2010.01.042. Epub 2010 Feb 4.

[4] Singh M1, Kaur M, Kukreja H, Chugh R, Silakari O, Singh D. Acetylcholinesterase inhibitors as Alzheimer therapy: From nerve toxins to neuroprotection. Eur J Med Chem. 2013;70:165-88. doi: 10.1016/j.ejmech.2013.09.050. Epub 2013 Oct 6 .

[5] Ellman GL, Courtney KD, Andres V Jr, Feather-stone RM. Anew and rapid colometric determination of acetylcholinesterase activity. Biochem Pharmacol. 1961;7:88-95.

[6] Weiss ES. An abridged table of probits for use in the graphic solution of the dosage-effect curve. Am J Public Health Nations Health. 1948;38(1 Pt 1): 22-4.

[7] Anikienko KA, Bychikhin EA, Reznik VS, Akamsin D, Galyametdinova IV. Compounds with the dioxopyrimidine cycle inhibit cholinesterases from different groups of animals. Chem Biol Interact. 2008;175(1-3):286-92. doi: 10.1016/j. cbi.2008.05.037. Epub 2008 Jun 8. 